\title{
Метод определения содержания примесей в трансформаторном масле по величине акустического коэффициента демпфирования
}

\author{
А. В. Крехова \\ Сибирский федеральный университет, Красноярск \\ eternity17@list.ru
}

УДК 621.314 .212

Статья поступила в редакцию 25.07.2019

Статья принята к публикации 20.09.2019

\begin{abstract}
Силовые трансформаторы - наиболее дорогие и стратегически важные компоненты любой энергосистемы. Для обеспечения надежности их работы и увеличения срока службы разрабатываются различные методы контроля и диагностики. Одним из перспективных является акустический метод обнаружения развивающихся дефектов путем регистрации акустических сигналов, которые возникают из-за присутствия примесей в трансформаторном масле. В статье приведены методика выполнения испытаний трансформаторного масла акустическим методом и способ обработки экспериментальных данных. В качестве критерия работоспособности по параметрам увлажненности и содержания целлюлозы рассматривается коэффициент демпфирования средой.
\end{abstract}

\section{ЭКСПЛУАТАЦИОННЫЕ \\ ПОКАЗАТЕЛИ КАЧЕСТВА ТРАНСФОРМАТОРНОГО МАСЛА}

Силовые трансформаторы являются наиболее дорогими и важными составляющими любой энергетической системы. В большинстве отраслей сложилась ситуация, когда основной фонд силового маслонаполненного электрооборудования изношен на 70-80\% [1]. Рост нагрузки сопровождается интенсивным старением фонда трансформаторов. Установлено, что после 50 лет эксплуатации происходит 50\% всех поломок, 60 лет - 90\%, 70 лет - 100\% (рис. 1) [2].

Современная система контроля и диагностики, предусмотренная РД [3], сосредоточена на проведении контроля трансформатора перед началом эксплуатации и после капитального ремонта. В таком виде невозможно в полной мере обеспечить надежность и безопасность их работы, поэтому актуальна разработка новых методов и подходов к определению реального технического состояния трансформаторов.

Одно из направлений связано с анализом трансформаторного масла как диагностической среды, отвечающей за износ изоляции трансформатора в целом. Среди множества качественных характеристик [1] для прогноза его технического состояния и дальнейшей работоспособности важными являются содержание влаги и целлюлозы.

Одна из причин увлажнения масла при эксплуатации образование воды в результате окисления углеводородов масла, ускоряемое при наличии электрического поля. Это, конечно, не исключает других источников увлажнения масла,

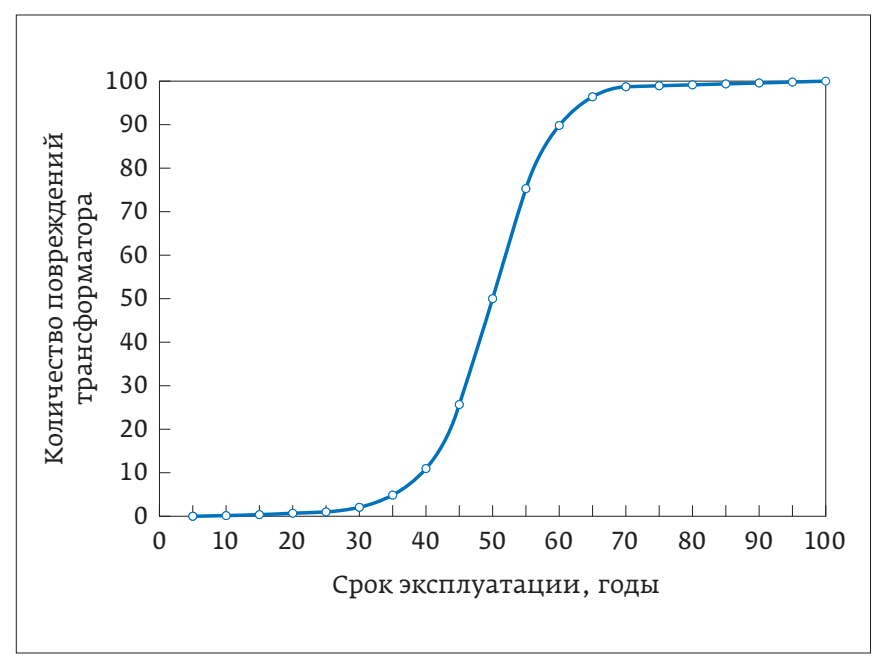

Puc. 1. Частота повреждений трансформатора как функция от срока эксплуатации [2] 
находящегося в рабочем трансформаторе, - из окружающего воздуха при колебаниях температуры, из целлюлозной изоляции за счет ее подсушки или же в результате глубокого старения целлюлозы [4]. При содержании влаги 3,3\% от массы твердой изоляции (что составляет 0,01 до 0,03\% массовой доли жидкой изоляции) от нее начинают отделяться волокна, а также снижается полная электрическая прочность изоляции трансформатора [5-7].

Поэтому параметры увлажненности и содержания целлюлозы в трансформаторном масле можно рассматривать как эксплуатационные показатели его качества.

Известны многочисленные методы определения влаги: титрирование Карла Фишера [8], построение диаграмм равновесия [9; 10], метод поляризационных и деполяризационных токов (PDC) [11], диэлектрические методы [12, 13], хроматографический метод [14-16], по ГОСт 7822-75 [17], согласно РД 34.43.107-95 [18] - и целлюлозы: инфракрасная спектроскопия с преобразованием Фурье (FTIR), спектроскопия в ближней инфракрасной области (NIR) [19], по ГОСТ 6370-83 [20]. К сожалению, они обладают рядом существенных недостатков:

- высокая трудозатратность;

- применение сложного дорогостоящего оборудования;

- проведение исследований в специализированных лабораторных условиях и помещениях;

- необходимость в высокой квалификации кадров, проводящих исследование.

Предлагаемый акустический метод базируется на исследовании влияния факторов износа трансформатора (увлажненности и содержания целлюлозы) на акустический спектр трансформаторного масла.

\section{МЕТОДИКА ИССЛЕДОВАНИЯ КАЧЕСТВА ТРАНСФОРМАТОРНОГО МАСЛА АКУСТИЧЕСКИМ МЕТОДОМ}

Условия проведения испытаний соответствуют гОСТ 8.395-80 [21].

Эксперименты проводили техническим методом по ГОСТ 12.1.027-80. Система стандартов безопасности труда. Шум. Определение шумовых характеристик источников шума в реверберационном помещении. Технический метод [22].

Испытательная установка состоит из образца трансформаторного масла, помещенного в резервуар, двух пьезокерамических преобразователей, генератора сигналов, персонального компьютера и программного обеспечения, структурная схема представлена на рис. 2.

Пьезоэлектрические преобразователи использовали в качестве излучателя и приемника, так как они могут не только генерировать ультразвуковой сигнал из электрической энергии, но и конвертировать механические колебания в электрические.

Принцип их работы основан на обратном пьезоэлектрическом эффекте, когда под действием электрического поля происходит механическая деформация кристалла, в результате возникают колебания.

Исследование влияния влаги на акустический спектр трансформаторного масла включало два основных этапа.

На первом этапе определяли вес образца эталонного трансформаторного масла, содержание влаги в котором составляет 0\%, и мощность звуковой волны, прошедшей через него, по 13 частотам в диапазоне от 1 до 10 кГц.

Далее с помощью пипетки по ГОСТ 29227-91 [23] в испытуемый образец масла добавляли воду. Полученную смесь взвешивали и определяли массовую долю влаги в пробе. Последующие измерения мощности звуковой волны проводили в трех точках процентной шкалы: 0,0994\%, 0,224\%, $0,355 \%[24]$.

Аналогичным образом исследовали влияние целлюлозы на акустический спектр трансформаторного масла 


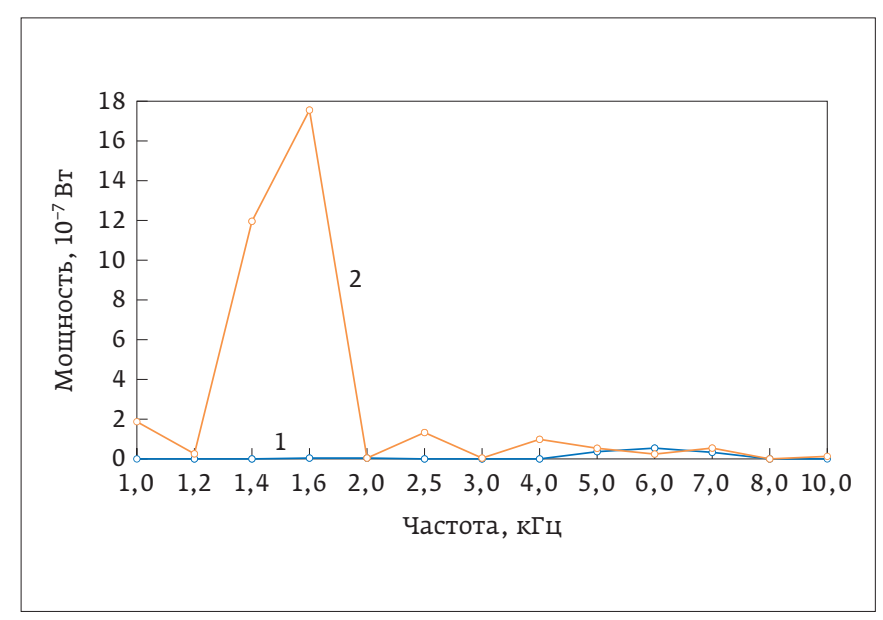

Puс. 3. Акустические спектры эталонного и отработанного трансформаторных масел: 7 - этапонное, 2- отработанное

в четырех точках процентной шкалы концентрации целлюлозы в образце трансформаторного масла: 0\%, 0,06\%, 0,18\%, 0,31\%. Суммарная относительная погрешность измерения массовой доли влаги и целлюлозы составила $\pm 0,005 \%$.

\section{МЕТОДИКА ОБРАБОТКИ ЭКСПЕРИМЕНТАЛЬНЫХ ДАННЫХ}

Обработка экспериментальных результатов включала шесть основных этапов: определение значимости влияния примесей, а затем отдельно влаги и целлюлозы, содержащихся в трансформаторном масле, на его акустический спектр; определение коэффициентов корреляции для установления вида зависимости между мощностью звуковой волны и содержанием влаги и целлюлозы; выбор несущих частот, которые мы связываем с содержанием влаги и целлюлозы в трансформаторном масле; составление соответствующих уравнений регрессии для несущих частот; определение адекватности полученных моделей. Оценку значимости проводили с помощью критерия Стьюдента при доверительной вероятности 95\%, оценку адекватности - с помощью критерия Фишера.

На первом этапе проведены эксперименты по определению частотных спектров эталонного трансформаторного масла (содержание примесей 0\%) и бывшего в эксплуатации трансформаторного масла (выработка примерно 10 тыс. часов). Спектры представлены на рис. 3, видно, что они сильно различаются.

С помощью критерия Стьюдента было показано, что примеси, присутствующие в трансформаторном масле, изменяют его акустический спектр. Доверительная вероятность составила $95 \%$.

На втором этапе обработки с помощью критерия Стьюдента также была подтверждена значимость влияния влаги и целлюлозы на акустический спектр трансформаторного масла (доверительная вероятность 95\%).

На третьем этапе определены коэффициенты корреляции, по величине которых выбраны несущие частоты:

- по частоте 2 кГц можно определить содержание влаги в трансформаторном масле (коэффициент корреляции $-0,96)$;

- по частоте 4 кГц можно определить содержание целлюлозы (коэффициент корреляции 0,94).

Так как коэффициенты корреляции близки кединице, следовательно, зависимость между концентрацией примесей и мощностью звуковой волны линейная.

Далее для несущих частот были составлены соответствующие уравнения регрессии и построены теоретическая и экспериментальная зависимости мощности звуковой волны от содержания примесей (рис. 4) [25].

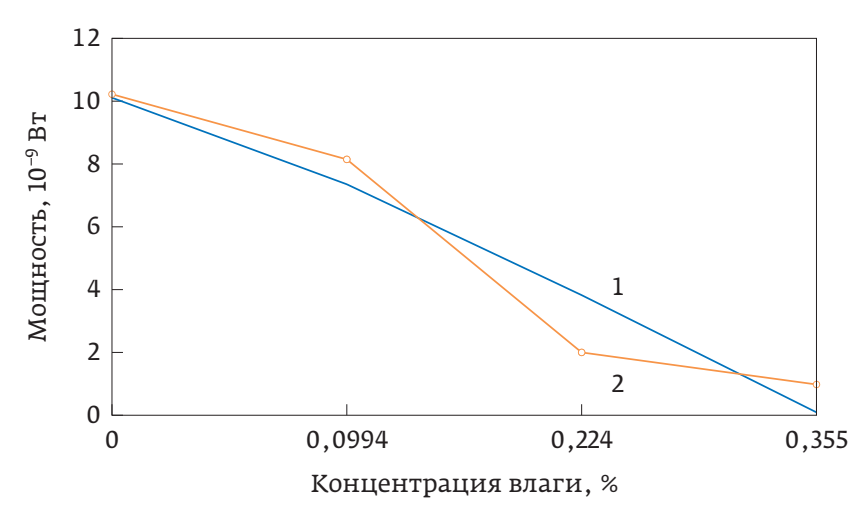

a)

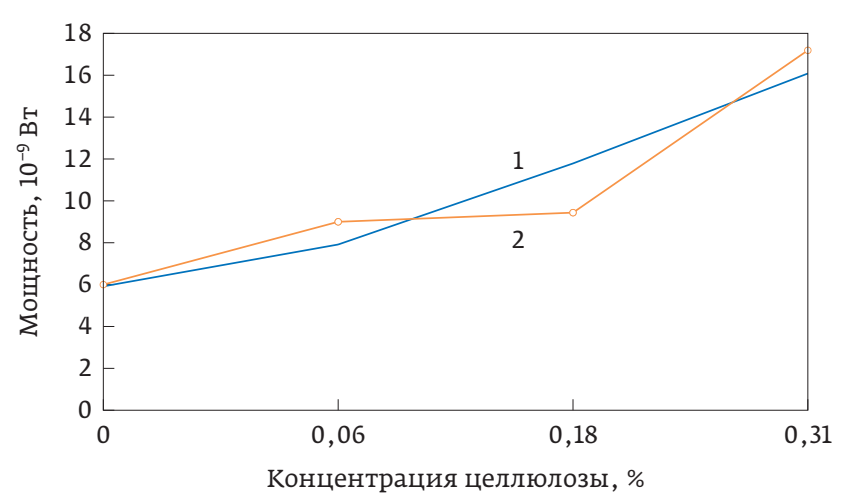

б)

Puc. 4. Теоретические и расчетные зависимости мощности звуковой волны от: а - содержания влаги на частоте 2 кГи, б-содержания целпюлозы на частоте 4 кГи, где 7 - теоретическая зависимость; 2 - экспериментальная 
Таблица 1. Результаты проверки адекватности моделей

\begin{tabular}{|l|c|c|}
\hline \multirow{2}{*}{ Характеристики } & Влага & Целлюлоза \\
\cline { 2 - 3 } & $\mathbf{2}$ кГц & 4 кГц \\
\hline $\begin{array}{l}\text { Расчетное значение F-отношения } \\
\text { Снекодера - Фишера }\end{array}$ & 0,31 & 0,49 \\
\hline $\begin{array}{l}\text { Табличное значение F-отношения } \\
\text { Снекодера - Фишера }\end{array}$ & \multicolumn{2}{|c|}{7,71} \\
\hline Коэффициент детерминации & 0,92 & 0,88 \\
\hline
\end{tabular}

Уравнения регрессии на несущих частотах 2 и 4 кГц имеют следующий вид:

$$
\begin{aligned}
& Y_{2 \mathrm{k} Г ц}=10,1 \cdot 10^{-9}-2,83 \cdot 10^{-8} \cdot X, \\
& Y_{4 \mathrm{~K} Г ц}=5,99 \cdot 10^{-9}+3,22 \cdot 10^{-8} \cdot X .
\end{aligned}
$$

На шестом этапе обработки проведена проверка адекватности полученных моделей по критерию Фишера, согласно которому гипотеза об адекватности уравнения регрессии принимается, если сохраняется расчетное значение F-отношения Снекодера - Фишера ниже табличного значения.

Также для анализа адекватности рассчитывают коэффициент детерминации, который показывает долю вариации результативного признака, находящегося под воздействием изучаемых факторов, то есть определяет, какая доля вариации признака Ү учтена в модели и обусловлена влиянием на него факторов, включенных в модель.

Результаты проверки полученных в ходе исследования регрессионных моделей сведены в табл. 1.

Так как расчетные значения F-отношения ниже табличных, а коэффициент детерминации высокий, то полученные модели адекватные и могут быть использованы

\begin{tabular}{|c|c|c|c|}
\hline \multirow[t]{2}{*}{ Примеси } & \multicolumn{2}{|c|}{ Мощность звуковой волны, Вт } & \multirow{2}{*}{$\begin{array}{c}\text { Коэффи- } \\
\text { циент } \\
\text { демпфи- } \\
\text { рования } \\
\text { средой }\end{array}$} \\
\hline & $\begin{array}{l}\text { Эталонное } \\
\text { трансфор- } \\
\text { маторное } \\
\text { масло }\end{array}$ & $\begin{array}{c}\text { Бывшее } \\
\text { в эксплуатации } \\
\text { трансформатор- } \\
\text { ное масло }\end{array}$ & \\
\hline $\begin{array}{l}\text { Влага } \\
\text { на частоте } \\
2 \text { кГц }\end{array}$ & $10 \cdot 10^{-9} \mathrm{BT}$ & $5,33 \cdot 10^{-9} \mathrm{BT}$ & 0,53 \\
\hline $\begin{array}{l}\text { Целлюлоза } \\
\text { на частоте } \\
4 \text { кГц }\end{array}$ & $6 \cdot 10^{-9} \mathrm{BT}$ & $101,30 \cdot 10^{-9} \mathrm{BT}$ & 16,88 \\
\hline
\end{tabular}

Таблица 2. Коэффициент демпфирования средой

для последующей оценки качества трансформаторных масел.

\section{КОЭФФИЦИЕНТ ДЕМПФИРОВАНИЯ СРЕДОЙ КАК КРИТЕРИЙ РАБОТОСПОСОБНОСТИ ТРАНСФОРМАТОРНОГО МАСЛА}

Основываясь на результатах экспериментов, в качестве критерия работоспособности трансформаторного масла по показателям увлажненности и содержания целлюлозы был выбран коэффициент демпфирования средой. Его определяли, как отношение измеренной мощности звуковой волны в образце бывшего в эксплуатации трансформаторного масла с примесями к мощности звуковой волны в образце эталонного трансформаторного масла (0\% содержание влаги и целлюлозы) на несущих частотах 2 и 4 кГц.

Используя регрессионный анализ, составлены соответствующие уравнения линейной регрессии и построены теоретические и экспериментальные зависимости коэффициента демпфирования средой от концентрации влаги и целлюлозы (рис. 5).

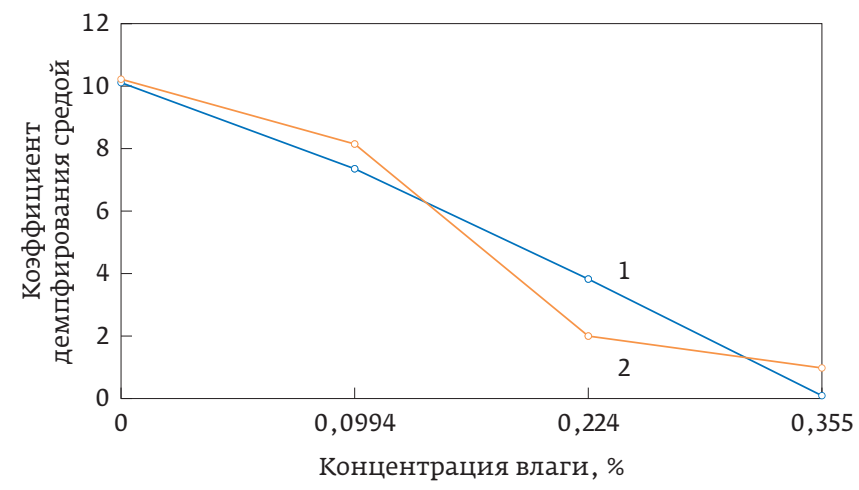

a)

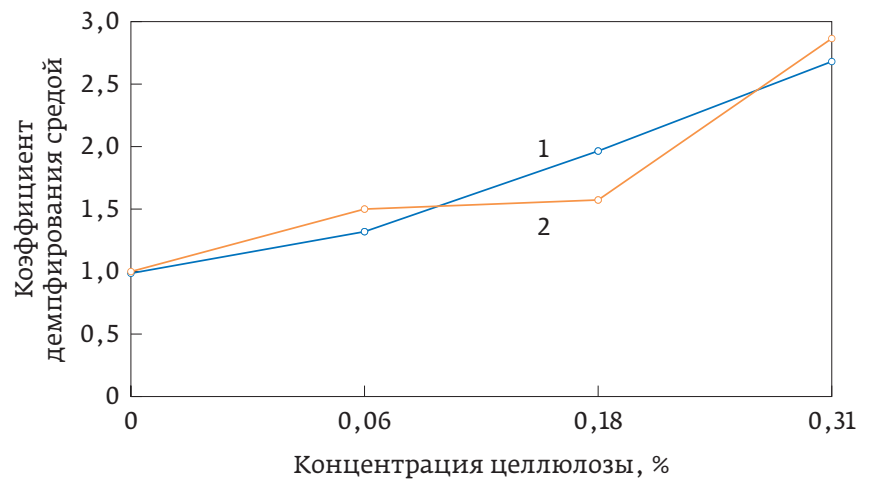

Puc. 5. Теоретическая и расчетная зависимости среднего коэффициента демпфирования среды от: а - концентрации влаги; 6- концентрации целпюлозы, где 7- теоретическая зависимость;2 - экспериментальная 


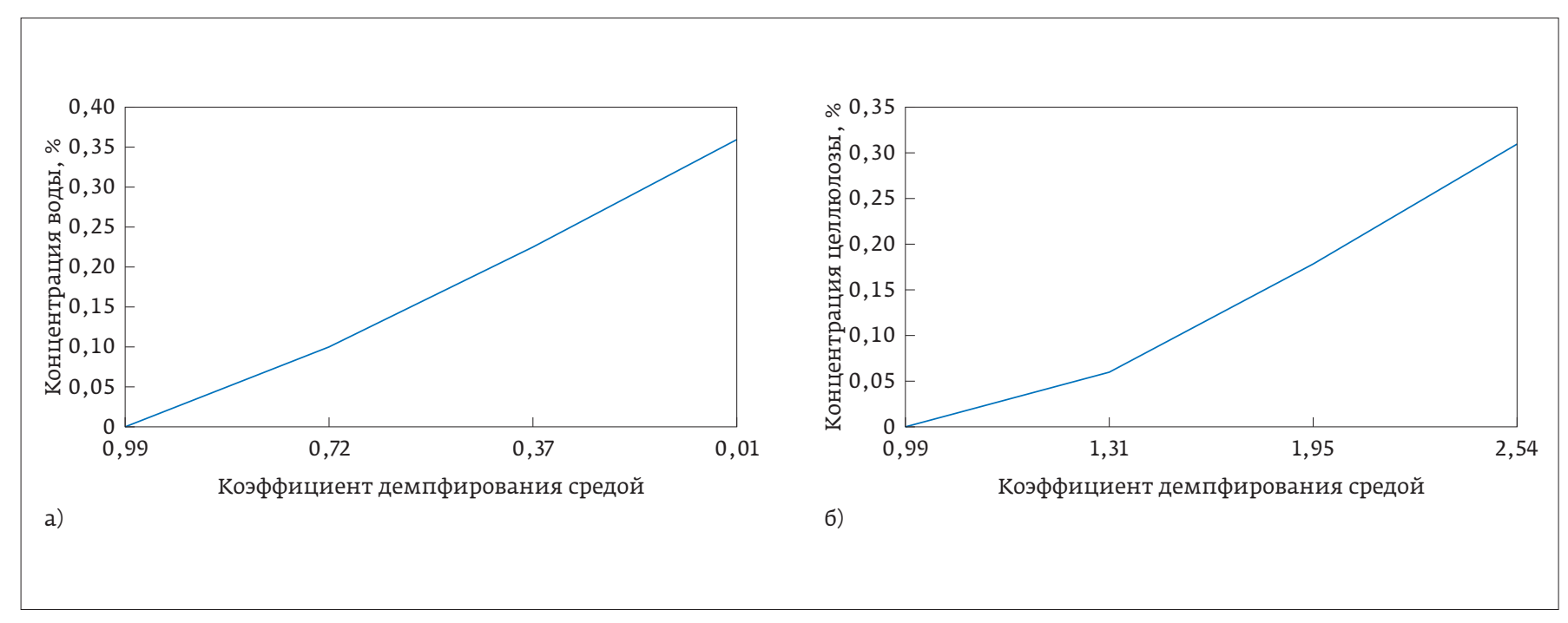

Puc. 6. Тарировочная кривая зависимости от коэффициента демпфирования средой: а - концентрации влаги; б - концентрации целююлозы

Уравнения регрессии на несущих частотах 2 и 4 кГц имеют следующий вид:

$$
\begin{aligned}
& Y_{\text {демпф. 2кГц }}=0,99-2,75 \cdot X, \\
& Y_{\text {демпф.4кГц }}=0,99+5,32 \cdot X .
\end{aligned}
$$

Полученные зависимости (см. рис. 5) можно использовать в качестве тарировочных кривых, когда по значению коэффициента демпфирования средой можно определить массовую долю влаги и целлюлозы, содержащихся в образце трансформаторного масла (рис. 6).

Что и было сделано для бывшего в эксплуатации трансформаторного масла, исследуемого на первом этапе.

численные значения мощности звуковой волны в эталонном и бывшем в эксплуатации трансформаторных маслах, а также рассчитанный коэффициент демпфирования средой сведены в табл. 2.

По найденной величине коэффициента демпфирования средой было установлено, что в исследуемом образце бывшего в эксплуатации трансформаторного масла марки Т-1500 массовая доля влаги составила 0,17\%, а массовая доля целлюлозы-2,99\%.

Полученные зависимости и экспериментальные данные подтверждают, что влага, имея большую плотность по сравнению с плотностью трансформаторного масла, увеличивает общую плотность среды и значение мощности звуковой волны, прошедшей через образец такого трансформаторного масла, уменьшается. Противоположным образом воздействует на плотность среды содержание целлюлозы: с увеличением количества целлюлозы в трансформаторном масле плотность среды уменьшается, в то время как мощность звуковой волны увеличивается. Эти результаты согласуются с данными других авторов, например, [5], где скорость в среде определяется по известной формуле:

$$
c=\sqrt{\frac{1}{\beta \rho}}
$$

где $\rho$ - плотность среды, $\beta$ - коэффициент адиабатического сжатия.

Из этого можно сделать вывод о том, что полученные модели могут быть использованы для определения эксплуатационных показателей качества трансформаторного масла - увлажненности и содержания целлюлозы. А акустический метод в силу его низкой трудоемкости и трудозатратности, отсутствия необходимости в сложном и дорогостоящем оборудовании, специальных лабораторных условиях и высокой квалификации проводящих исследования кадров является перспективным методом для дальнейшего внедрения в систему диагностики и контроля силовых трансформаторов.

\section{ЛИТЕРАТУРА}

1. Батрак А. П., Тюрюмина А. В., Никитина А. В. Сравнение качественных характеристик трансформаторных масел // Тяжелое машиностроение. 2013. № 3. С. 41-44.

2. Metwally I.A. Failures, monitoring, and new trends of power transformers // IEEE potentials. 2011, May/June. Р. 36-43.

3. РД 34.45-51.300-97. Объем и нормы испытаний электрооборудования. 6-е изд. URL: https://files.stroyinf.ru/Data1/11/11967/.

4. Липштейн Р. А., Шахнович М. И. Трансформаторное масло / 3-е изд., перераб. и доп. - М.: Энергоатомиздат, 1983. 296 с.

5. Красильников В. А., Крылов В. В. Введение в физическую акустику. - М.: Наука, 1984. 403 C.

6. Батрак А. П., Тюрюмина А. В., Никитина А. В. Факторный анализ качественных характеристик трансформаторного масла в 3 т. Т. 3 // Молодежь и XXI век - 2015: материалы V Междунар. молодеж. науч. конф. (26-27 февраля 2015 г.), Юго-Зап. гос. ун-т, ЗАО "Университетская книга». - Курск, 2015. 259 с.

7. Алексеев Б.А. Контроль состояния (диагностика) крупных силовых трансформаторов. - М.: НЦ ЭНАС, 2002. - 216 с. 
8. Koch M., Tenbohlen S., Blennow J., Hoehlein I. Reliability and improvements of water titration by the Karl Fischer technique / 15 th ISH, August 27-31, 2007, Ljubljana, Slovenia.

9. Fabre J., Pichon A. Processes and products of paper in oil. Application to transformers // International Conference on Large High Voltage Electric System (CIGRE), paper 137, Paris, France, 1960.

10. Oommen T. V. Moisture equilibrium in paper-oil systems, Electrical / Electronics Insulation Conference, Oct. 3-6, 1983, Chicago.

11. Leibfried T., Kachler A. J. Insulation diagnostics on power transformers using the epolarizati and epolarization current (PDC) analysis // IEEE International Symposium on Electrical Insulation, April 7-10, 2002, Boston, MA USA.

12. Koch M., Krüger M. A fast and reliable dielectric diagnostic method to determine moisture in power transformers // International Conference on Condition Monitoring and Diagnosis, April 21-24, 2008, Beijing, China.

13. Gradnik T., Konkan-Gradnik M., Petric N., Muc N. Experimental evaluation of water content determination in transformer oil by moisture sensor // IEEE International Conference on Dielectric Liquids, Trondheim, 2011

14. Бузаев В. В. Роль физико-химических методов анализа в системе оценки состояния трансформаторного оборудования // Тр. науч.практ. семинара по проблеме диагностики электрической изоляции. - Новосибирск, 2004.

15. Чупак Т.М. Прогнозирование технического состояния силовых маслонаполненных трансформаторов: автореф. дис. ... канд. техн. наук: 05.14.02. - Красноярск, 2007. 20 с.

16. Давиденко И. В. Разработка системы многоаспектной оценки технического состояния и обслуживания высоковольтного маслонаполненного электрооборудования: автореф. дис. ... канд. техн. наук: 05.14.02. - Екатеринбург, 2009. 46 с.

17. ГОСТ 7822-75. Масла нефтяные. Метод определения растворенной воды. URL: http://docs.cntd.ru/document/1200004512.

18. РД 34.43.107-95. Методические указания по определению содержания воды и воздуха в трансформаторном масле. URL: https://files. stroyinf.ru/Index2/1/4294844/4294844653.htm

19. Ali M., Emsley A. M., Herman H., Heywood R. J. Spectroscopic studies of the ageing of cellulosic paper // Heywood Polymer. 2001 V. 42. P. 2893-2900.

20. ГОСТ 6370-83 (СТ СЭВ 2876-81). Нефть, нефтепродукты и присадки. Метод определения механических примесей. URL: http://docs. cntd.ru/document/1200004078.

21. ГОСТ 8.395-80. Государственная система обеспечения единства измерений. Нормальные условия измерений при поверке. Общие требования. [Электронный ресурс]. - Режим доступа: http://docs. cntd.ru/document/gost-8-395-80-gsi.

22. ГОСТ 12.1.027-80. Система стандартов безопасности труда. Шум. Определение шумовых характеристик источников шума в реверберационном помещении. Технический метод. [Электронный ресурс]. - Режим доступа: http://docs.cntd. ru/document/5200305

23. ГОСТ 29227-91. Посуда лабораторная стеклянная. Пипетки градуированные. Часть 1. Общие требования. [Электронный ресурс]. Режим доступа: http://docs.cntd.ru/document/1200024087.

24. Батрак А. П., Чупак Т. М., Тюрюмина А. В., Никитина А. В. Акустический анализ свойств трансформаторных масел // Тяжелое машиностроение. 2014. № 4-5. С. 45-46.

25. Tyuryumina A., Batrak A. and Sekackiy V. Determination of transformer oil quality by the acoustic method // MATEC Web of Conferences. 2017. 113 p.

\section{REFERENCES}

1. Batrak A. P., Tyuryumina A. V., Nikitina A.V. The Comparison of Transformer Oil Quality Characteristics. Tjazheloe mashinostroenie Heavy equipment industry, 2013, no. 3, pp. 41-44.

2. Metwally I. A. Failures, monitoring, and new trends of power transformers. IEEE potentials, 2011, May/June. pp. 36-43.

3. RD34.45-51.300-97. Scope and standards of tests of electrical equipment. 6th edition. Available at: https://files.stroyinf.ru/ Data1/11/11967/4.
4. Lipstein R. A., Shakhnovich M.I.Transformer oil. - Moscow: Energoatomizdat Publ., 1983

5. Krasilnikov V. A., Krylov V. V. Introduction to physical acoustics. Moscow: Science Publ., 1984.

6. Batrak A. P., Tyuryumina A. V., Nikitin A. V. Factor analysis of quality characteristics of transformer oil. Molodezh" i XXI vek-2015 materialy $\vee$ Mezhdunarodnoj molodezhnoj nauchnoj konferencii Youth and the XXI century - 2015: Materials of the V International Youth Scientific Conference, Southwest state university, CJSC Universitetskaya kniga Publ. - Kursk, 2015. 259 p.

7. Alekseev B.A. Control of a state (diagnostics) of large power transformers. - Moscow, NTs ENAS Publ., 2002.

8. Koch M., Tenbohlen S., Blennow J., Hoehlein I. Reliability and improvements of water titration by the Karl Fischer technique. 15th ISH, Ljubljana, 2007.

9. Fabre J., Pichon A. Processes and products of paper in oil. Application to transformers. International Conference on Large High Voltage Electric System (CIGRE), Paris, 1960.

10. Oommen T. V. Moisture equilibrium in paper-oil systems. Electrical/ Electronics Insulation Conference, Chicago, 1983.

11. Leibfried T., Kachler A. J. Insulation diagnostics on power transformers using the epolarizati and epolarization current (PDC) analysis. IEEE International Symposium on Electrical Insulation, Boston, 2002.

12. Koch M., Krüger M. A fast and reliable dielectric diagnostic method to determine moisture in power transformers. International Conference on Condition Monitoring and Diagnosis, Beijing, 2008.

13. Gradnik T., Konkan-Gradnik M., Petric N., Muc N. Experimental evaluation of water content determination in transformer oil by moisture sensor. IEEE International Conference on Dielectric Liquids, Trondheim, 2011.

14. Buzayev V.V. A role of the physical and chemical analysis methods in the assessment system of the transformer equipment condition. A scientific and practical seminar on a problem of diagnostics of electric isolation, Novosibirsk, 2004

15. Chupak T. M. Of Technical condition forecasting of power oil-filled transformers, Thesis ... cand. of tech. Sci. Krasnoyarsk, 2007.

16. Davidenko I.V. Development of the multidimensional assessment system of technical condition and service of high-voltage oil-filled electric equipment, Thesis ... cand. of tech. Sci. Yekaterinburg, 2009.

17. GOST 7822-75 Petroleum oils. Method of dissolved water. Available at: http://docs.cntd.ru/document/1200004512.

18. RD34.43.107-95. Procedural Guidelines for the Determination of Content of Water and Air in Transformer Oil. Available at: https:// files.stroyinf.ru/Index2/1/4294844/4294844653.htm

19. Ali M., Emsley A. M., Herman H., Heywood R. J. Spectroscopic studies of the ageing of cellulosic paper. Heywood Polymer, 2001, v. 42 , pp. 2893-2900.

20. GOST 6370-2018 Petroleum, petroleum products and additives. Method for determination of mechanical admixtures. Available at: http://docs.cntd.ru/document/1200160609.

21. GOST 8.395-80. State system for ensuring the unity of measurements. Normal calibration measurement conditions. General requirements. Available at: http://docs.cntd.ru/document/ gost-8-395-80-gsi.

22. GOST 12.1.027-80. Occupational Safety Standards System. Noise Determination of noise characteristics of noise sources in the reverberation room. Technical method. Available at: http://docs. cntd.ru/document/5200305.

23. GOST 29227-91. Lab glassware. The pipettes are graduated. Part 1. General requirements. Available at: http://docs.cntd.ru/ document/1200024087

24. Batrak A. P., Tyuryumina A. V., Nikitina A. V. The acoustic analysis of transformer oil properties. Tjazheloe mashinostroenie - Heavy equipment industry, 2014, no. 4-5, pp. 45-46.

25. Anastasiya Tyuryumina, Andrey Batrak and Victor Sekackiy. Determination of transformer oil quality by the acoustic method. MATEC Web of Conferences, 2017, $113 p$. 